\title{
ePortfolio and Service-Learning: A Tale of Two Cities Connected by Two High-Impact Practices
}

\author{
https://doi.org/10.3991/ijet.v15i05.12087 \\ Monika Ciesielkiewicz $(\square)$ \\ Villanueva-Complutense University of Madrid, Madrid, Spain \\ mciesielkiewiczevillanueva.edu \\ Clarence Chan \\ LaGuardia-City University of New York, New York, USA \\ Guiomar Nocito \\ Villanueva-Complutense University of Madrid, Madrid, Spain
}

\begin{abstract}
Two different post-secondary professional education programs from two different cities (New York and Madrid) took a similar approach in using ePortfolio to facilitate high-impact behaviors (HIBs) among their students while showing how the ePortfolio enhances and supports other high impact practices (HIPs). In Madrid, ePortfolio was utilized to support a Matumaini Project as it integrated the academic work carried out in the classrooms to help a community in Kenya. On the other side of the Atlantic, the ePortfolio was implemented in order to connect didactic learning from the classroom to the clinical practice in the local community. Both case studies suggested that the ePortfolio combined with other high-impact practices plays a complementary role with other High-Impact Practices (HIPs) in higher education. Our statistical analysis sheds light on the relationship between seven high-impact behaviors present when two high-impact practices are combined. The correlations, both combined and by city, demonstrate the importance of promoting two highimpact behaviors in particular, which are: 1) quality interaction between the students and the professors and 2) providing opportunities to relate academic learning to real world experiences. When these two high-impact behaviors were maximized, our data suggest that the use of other high-impact behaviors examined in this study expanded as well. This research also confirms the importance of providing students a way to relate their classroom learning with real-world experiences.
\end{abstract}

Keywords - ePortfolio; high-impact educational practices; high-impact behaviors; service-learning; internship; higher education.

\section{Introduction}

In the quest for delivering quality and value in higher education while continue to maintain high degree of accountability, meet the limits of financial constraints, and 
elevate completion and employment rates, academic institutions are constantly looking for ways to develop and enhance their educational practices that can have significant impact on student learning with demonstrable outcomes [1, 2]. Student's academic success is often determined by many factors. The level of sustained engagement and the ability to integrate their formal and informal curricula both in and outside of the classroom, to name a few, are often considered key components to determine student learning [3, 4, 5]. The Association of American Colleges and Universities (AAC\&U) has been promoting many innovative projects to meet these ongoing demands. Among them was a report published between 2007 and 2008 by George Kuh [6] that defined 10 High-Impact Practices (HIPs). These pedagogical practices have been tested and shown to be highly effective in encouraging active learning through student/faculty engagement, peer interactions, and experiential learning [7]. Initially there were 10 practices: first-year seminars, common intellectual experiences, learning communities, writing-intensive courses, collaborative assignments and projects, undergraduate research, diversity/global learning, service learning/community-based learning, internships, and capstone courses and projects [8]. Recently in 2017, ePortfolio also became the 11th addition to the list of HIPs $[9,10]$ "Evidence from multiple institutions shows these practices 'have special benefit' on student outcomes such as engagement, persistence, retention, higher GPA, and graduation from college [9]." Although HIPs can be demonstrated in different forms depending on institutional/program needs, and student demographics and characteristics; when done well, all HIPs shared similar features and had similar effect on student learning. Collectively these key learning features or behaviors called High Impact Behaviors (HIBs) are as follows [10, 11, 12].

- Significant investment of concentrated effort by students over an extended period of time

- Interactions with faculty and peers about substantive matters

- Experiences with diversity, wherein students are exposed to and must contend with people and circumstances that differ from those with which students are familiar

- Frequent, timely, and constructive feedback

- Opportunities to discover relevance of learning through real-world applications

- Public demonstration of competence

- Periodic, structure opportunities to reflect and integrate learning

Singularly, and even more powerful when combined, HIPs promote these key learning practices and behaviors that can exponentially elevate student's learning experiences and academic success $[13,14,15,16,17,18]$. Ultimately, "HIPs promise to change and improve on the institutional policies and practices we inherited by drawing on what we know about high quality learning and engagement [10]" (p. 15).

This paper explores how two post-secondary professional programs from two different cities took a similar approach in using ePortfolio to facilitate high impact behaviors among their students while showing how ePortfolio functions as meta highimpact practice to support other high-impact practices. This case study set out to explore both the similarities and the differences in the two programs, and what we learned from each other's development. 


\section{1 ePortfolio as integrative social pedagogy and reflective practice}

To do well with ePortfolio, it was clearly stated by Eynon and Gambino [19] that integrative social pedagogy must be central to the ePortfolio practice. "Connecting and making meaning from diverse learning experiences helps students develop more purposeful identities as learners. Reflecting in community-sharing and discussing their learning with others-adds depth and power to integrative learning" (p. 38). Diller and Phelps [20] also assert that ePortfolios aid students to make connections between their course and extra-curricular activities. Making meaning and connections with a diverse set of learning experiences through thoughtful examination of self can deepen one's learning [19, 21, 22, 23, 24].

Eynon and Gambino (2017) [9] as well as Hanum, Che-Ani, Johar, Ismail and Razak [25] also stated that effective ePortfolio pedagogy requires careful and deliberate guidance from faculty and mentors in order to yield successful outcome. Directions, feedback, and technological supports are essential to the student's sustained engagement and appreciation. Furthermore, proper course or programmatic design sequence of application is also necessary to maximize the integrative effect. In short, an integrative learning experience with ePortfolio can be achieved either with a single course or across an entire program as long as it is supported by a sustained, thoughtful, and coordinated ePortfolio integration. As noted by education scholars, practitioners, reflection is the key component of any successful integrative ePortfolio learning experience $[6,9,10,16,26,27,28,29,30,31,32]$. Meaningful and powerful reflections enhance personal development through change in attitude and behavior, which in and of itself can be considered a high-impact behavior [6, 9, 10, 33].

Combining with other high-impact behaviors, such as enhancing interactions with faculty and peers, identifying relevance through real-world applications, and publicly demonstrating competence, as defined by Kuh and O'Donnell [12] (p. 8), ePortfolio serves as the ideal platform to nurture and support other high-impact practices [15].

\section{2 ePortfolio as meta high-impact practice}

According to Eynon and Gambino [9], their experience with the Connect to Learning (C2L) project suggested ePortfolio practices was highly effective in facilitating the goals and outcomes of other high-impact practices. Their research experiences demonstrated the positive role of ePortfolio in first-year experiences, internships and service-learning, and capstone courses as a meta high-impact practice. The research teams from $\mathrm{C} 2 \mathrm{~L}$ also confirmed that ePortfolio shared similar characteristics of other HIPs in several ways. For example, institutions such as Guttman, Salt Lake Community College, and Boston University utilized ePortfolio to support their students' study aboard experiences. St. John's University's Teacher Preparation Program and Three Rivers Community College's Nursing Program both took advantage of ePortfolio as a reflective tool to support their student professional development.

All high-impact practices were designed to address student's personal growth by drawing on both academic and lived experiences $[10,16]$. They thrived on connection 
and integration and encouraged faculty to challenge students to develop high-impact learning behaviors. What made ePortfolio most uniquely qualified to be the meta high-impact practice is its longitudinal nature, which in turn allows students to track, witness, and showcase their entire learning experience by linking their coursework to co-curricular activities and to personal experiences [9, 15, 16, 33, 34, 35]. Therefore, ePortfolio done well should position it as the vehicle that linked a range of learning experiences that are truly "joined at the HIP" [9] (p. 193).

\section{Two Cities, Two Programs}

The two professional programs from the two cities, both employed ePortfolio as Integrative Social Pedagogy to facilitate High-Impact learning behaviors. Both programs took advantage of ePortfolio as meta-HIP to complement other HIPs.

In Madrid, students have participated in MaTumaini Service-Learning Project as it integrates the academic work carried out in the classrooms to help the Maasai Community in Kenya for the past 2 years. Different projects were undertaken by students from the schools of Education, Media Studies, and Business within the higher education framework from which they obtain academic credits.

The research data for this study are a result of the Service-Learning project that was part of an Information and Communication Technologies (ICT) in Education course. The participants of this study are all from the School of Education. They were enrolled in two asynchronous undergraduate sections of an elective course on ICTs in Education (Academic Years 2015-2016 \& 2016-2017). They were all preschool and primary education students that developed didactic materials to teach basic computer skills such as video tutorials, a textbook and an exercise book. These materials had been requested by the Maasai Community Primary School teachers who have been directed by Kenya's Department of Education to teach computer courses and found themselves with no knowledge, training or resources. This project in particular, as well as the others included in the MaTumaini Service-Learning Initiative, addresses real needs that the Maasai community expressed explicitly and asked to help them with.

The integration of ePortfolios into MaTumaini Service-Learning project was a means for helping students to reflect on their Service-Learning experience as well as to integrate their knowledge in a real-world context. It has served to deepen learning and to support students' abilities to articulate skills and knowledge developed through this project. It has provided each student a platform to document, reflect on, and showcase their work. In their ePortfolios, students shared a series of reflections in which they explored issues that addressed social justice, privilege, giving back to the community, and social responsibility. Prompts based on Bloom's Reflection Taxonomy were provided to help students reflect on the process of designing didactic materials, finding their own meaning of the Service-Learning experience and thinking of ways they could apply what they have learned in the future and get involved in similar types of projects. 
The ePortfolio served as a high-impact practice that amplified the effectiveness of the Service-Learning experience. It also helped to make them aware that they can have a meaningful impact on other people's lives with knowledge that they usually take for granted. Additionally, the Service-Learning experience combined with the ePortfolio allows students to make their work visible and public. It showcases the unique professional experience of designing teaching materials for a community in need.

On the other side of the Atlantic, the Physical Therapist Assistant (PTA) program has been pioneering in the use of ePortfolio as a teaching and learning tools to promote student engagement, integrate student learning, and demonstrate student growth since 2003. Over the past decade the program systematically migrated from a course based ePortfolio structure to a platform that span across the entire curriculum. The PTA Student Professional ePortfolio became a required element to help students connect their learning experiences from pre-clinical (general education) courses, clinical phase of training, and clinical affiliation [37]. This program wide pedagogical and outcomes assessment approaches are grounded on what Eynon and Gambino [9] described as the Catalyst Framework's Learning Core (p. 28) with full institutional, programmatic, and faculty supports.

With the mission to prepare students to become ethical and competent health care providers, the PTA program utilizes the ePortfolio to facilitate and support students' development in physical therapy professional core values such as altruism, compassion/caring, lifelong learning, and social responsibility, which are competencies essential to be a well-rounded clinician. The acquisition of these important professional qualities can only be nurtured by many of the high impact learning experiences or behaviors as described by Kuh and others $[6,12,16,38]$. The Commission on Accreditation in Physical Therapy Education [39] also expects all physical therapy programs to develop and assess students' competence in all three domains as described in the Bloom's Taxonomy.

Mirrored the design principles described by Eynon and Gambino [9] (p. 32-36), inquiry, reflection, and integration are the design elements that guided the development of the PTA ePortfolio structure. Students can make meaningful connections with what they learned from the classroom and lab to experiences gained from their internship and community engagement.

New York case study focuses on how the PTA Student Professional ePortfolio fosters high-impact behaviors while reinforces the value of clinical internship through a series of systematic self-reflection and peer assessment. It's a model based on the Integrative Social Pedagogy, one of the five interlocking sectors of the Catalyst framework developed by Eynon and Gambino [9] (p. 29).

\section{$3 \quad$ Method}

For the purposes of this study the authors used an online survey administered through Google Forms. The high-impact behavior questionnaire for both cities consisted of questions with a five-point Likert scale with the range of responses from 
strongly disagree (1) to strongly agree (5). There were also open questions regarding high-impact behaviors. Both surveys had questions in common regarding the seven high-impact behaviors.

There were no missing values for either survey. The internal reliability of the survey results was examined. The Cronbach's alpha for the combined responses of both cities is .9 which is considered excellent. The New York results had a Cronbach's alpha of .9 while the reliability for the Madrid results was lower, though still acceptable value of .7. The Madrid survey had 39 respondents $(\mathrm{N}=39)$ with a $77 \%$ response rate. The New York survey had 29 respondents $(\mathrm{N}=29)$ with a 53\% response rate.

\section{$4 \quad$ Results}

\subsection{Comparisons of high-impact behaviors}

Overall, Madrid respondents rated the service-learning/ internship combined with the ePortfolio activity higher than their counterparts in New York. Table 1 shows a statistical summary of all responses for both cities. It is important to note that the mean of all items for Madrid is 4.3 (xMADRID = 4.3) while the mean of the New York responses is 2.7 (xNEW YORK = 2.7). The responses from Madrid also had a smaller range (0.41) than those of New York (0.86).

Table 1. Statistical summary of responses.

\begin{tabular}{|l|c|c|c|c|}
\hline \multicolumn{1}{|c|}{ Country } & M & Min & Max & Range \\
\hline Madrid & 4.32 & 4.12 & 4.53 & 0.41 \\
\hline New York & 2.73 & 2.41 & 3.28 & 0.86 \\
\hline
\end{tabular}

The means of the Madrid survey were higher for each of the high-impact behaviors examined. The largest mean in the Madrid Survey was for the question about interaction, while this was the second lowest mean for the New York responses. It is also interesting to note that the second highest mean for the Madrid responses was the item about feedback, while this was the lowest mean for the respondents in New York. Table 2 summarizes the means for each high-impact behavior by city.

Table 2. Means of responses for each high-impact behavior.

\begin{tabular}{|l|l|c|c|}
\hline High-Impact Behavior & \multicolumn{1}{|c|}{ City } & M & SD \\
\hline \multirow{2}{*}{ Time } & Madrid & 4.13 & 0.73 \\
\cline { 2 - 4 } & New York & 2.90 & 1.01 \\
\hline \multirow{2}{*}{ Interaction } & Madrid & 4.54 & 0.64 \\
\cline { 2 - 4 } & New York & 2.48 & 1.27 \\
\hline \multirow{2}{*}{ Cultural Diversity } & Madrid & 4.31 & 0.69 \\
\cline { 2 - 4 } & New York & 2.62 & 1.11 \\
\hline \multirow{2}{*}{ Feedback } & Madrid & 4.41 & 0.71 \\
\cline { 2 - 4 } & New York & 2.41 & 1.15 \\
\hline
\end{tabular}




\begin{tabular}{|l|l|c|c|}
\hline \multirow{2}{*}{ Reflection } & Madrid & 4.31 & 0.61 \\
\cline { 2 - 4 } & New York & 2.72 & 1.16 \\
\hline \multirow{2}{*}{ Academic/Real World } & Madrid & 4.26 & 0.85 \\
\cline { 2 - 4 } & New York & 2.72 & 1.92 \\
\hline \multirow{2}{*}{$\begin{array}{l}\text { Demonstration of } \\
\text { Competencies }\end{array}$} & Madrid & 4.31 & 0.65 \\
\cline { 2 - 4 } & New York & 3.28 & 1.41 \\
\hline
\end{tabular}

\subsection{Time invested in the activity}

As noted in Table 2, Participants in Madrid reported having spent more time on this project than those in New York $(x N E W$ YORK $=2.90$; MADRID $=4.13$ ). A chi-square test of independence was performed to examine the relationship between Madrid and New York with regard to time invested in the project. The relation between these variables was significant, X2 $(4$, NMadrid $=39$, NNewYork $=29)=$ $25.29, \mathrm{p}<.01$, which indicate that this finding is statistically significant. Figure 1 provides a graphical representation of the responses to this item.

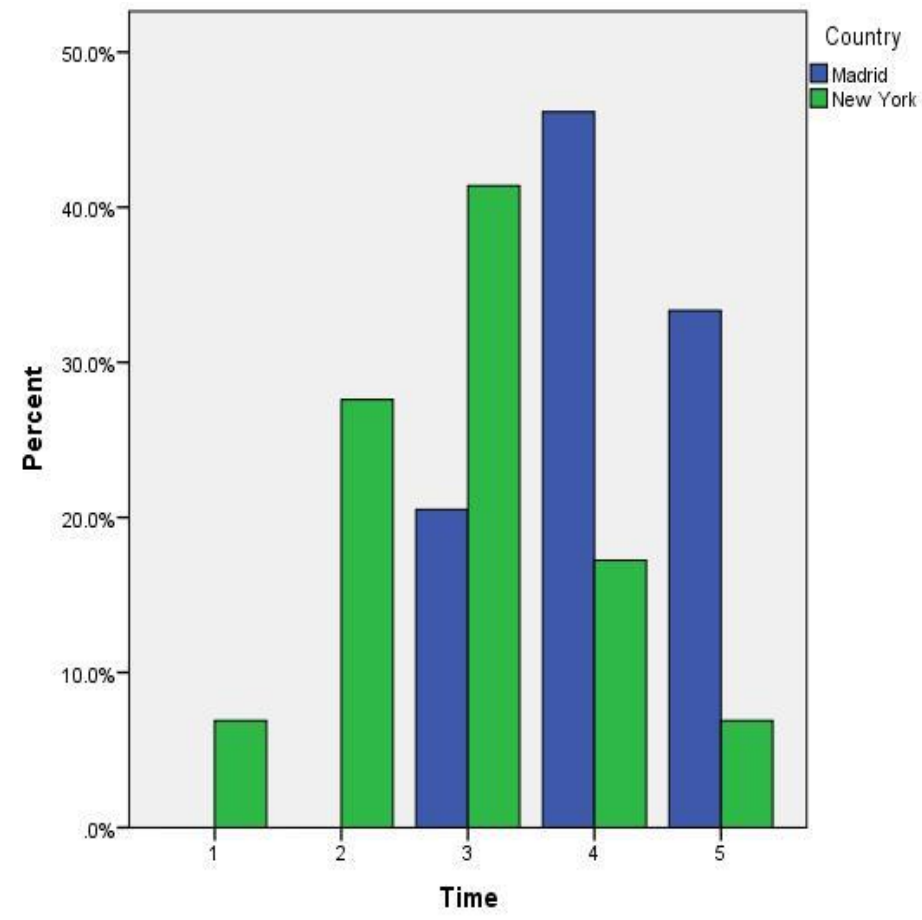

Fig. 1. Student responses regarding having spent a significant amount of time on the project. (1 $=$ Strongly Disagree, $5=$ Strongly Agree) 


\subsection{Reported interaction during the activity}

As previously noted, the mean for the interaction in Madrid was the highest of all of the high-impact behaviors, while in New York it was the second lowest $(\mathrm{xMADRID}=4.54 ; \mathrm{xNEW}$ YORK $=2.48 \mathrm{p}<.01)$. A chi-square test of independence was performed to examine the relationship between Madrid and New York with regard to interaction during the project. The relation between these variables was significant, X2 $(4$, NMadrid $=39$, NNewYork $=29)=38.52, p<.01$. This result is graphically represented in figure 2 .

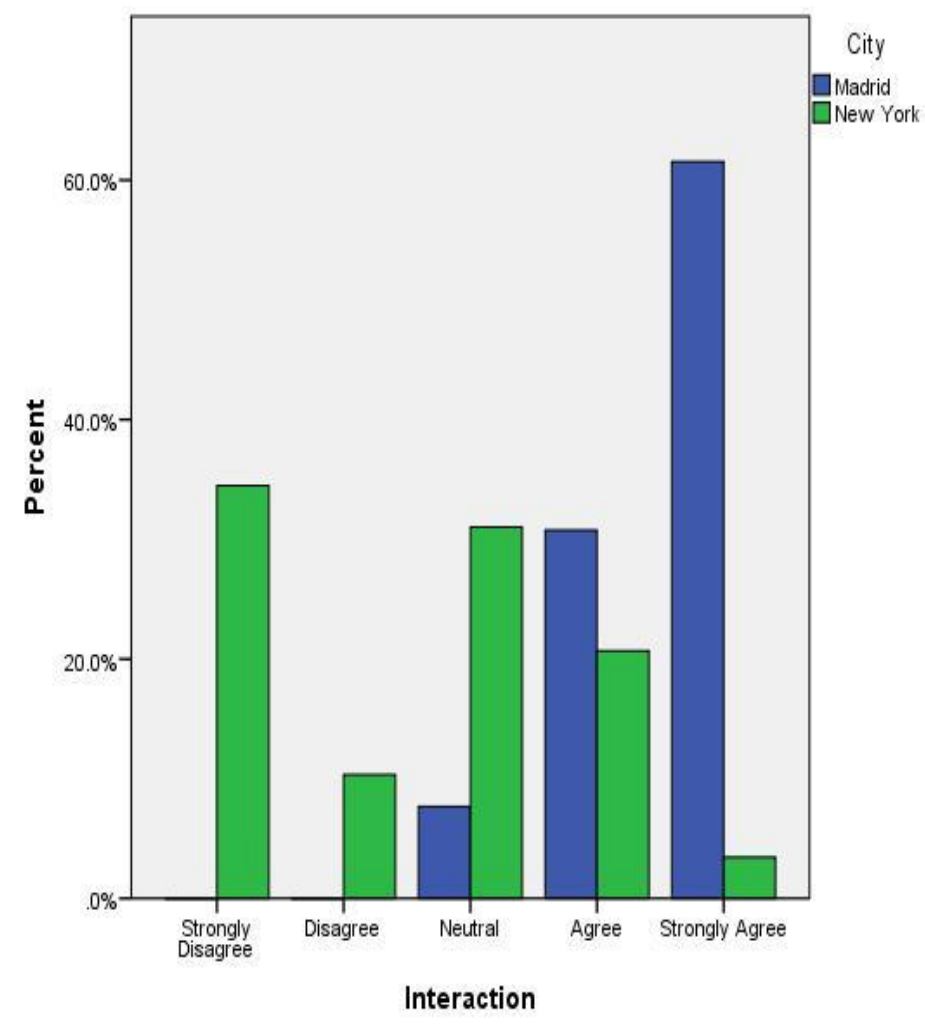

Fig. 2. Responses regarding interaction with other students and professors during the activity.

As one may expect, some students from New York were quite clear that ePortfolio was neither preferred method for interaction nor the most effective in their estimation.

- ePortfolio didn't really facilitate any significant interactions relating to my Clinical Internship. Interactions in person during class meetings were much more impactful.

- I will write some journals about my clinical internship experience and post to my ePortfolio, but I have never received any comments or feedback from faculty and peers. 
- I am (sic) concentrated studying (sic), writing my projects and going to my clinical practices, that I'am (sic) really don't have time to look the ePortfolios of my classmates.

However, several of the students from New York endorsed the ePortfolio for interaction. Examples are included below:

- In the clinic, there are something different than what we learned in school. This is a place where we can communicate with faculty efficiently.

- ePortfolio helped me to become a better clinician

Although Spain consistently gave their interactions through ePortfolio positive evaluations, the difficulty of working in a large group for this project was a recurring theme in the comments. Examples follow:

- The interaction with colleagues was difficult in some cases because there were many in my group and coordination was sometimes complicated, but in the end, we managed to coordinate well, and the project has gone very well. As for the teacher, she has always helped us in everything and has been available to us at all times.

- We had six members in our group and because of that situation we had to work separately most of the time.

- There were six people in my group, and we have gotten along well so as to distribute tasks, but it would be advisable that the next time there could be fewer people. The advantage though, is the fact that we finished so fast.

\subsection{Cultural diversity}

There was a potential to expose students to cultural diversity for both groups. The students in New York had contact with patients from various countries, while the students in Madrid prepared materials for a school in Kenya. The students were asked about their level of agreement to the statement that the service-learning/ internship combined with the ePortfolio activity helped students think about cultural diversity. A chi-square test of independence was performed to examine the relationship between Madrid and New York with regard to cultural diversity. The relation between these variables was significant, X2 $(4$, NMadrid $=39$, NNewYork $=29)=34.29, \mathrm{p}<.01$. The results are displayed graphically in Figure 3. 


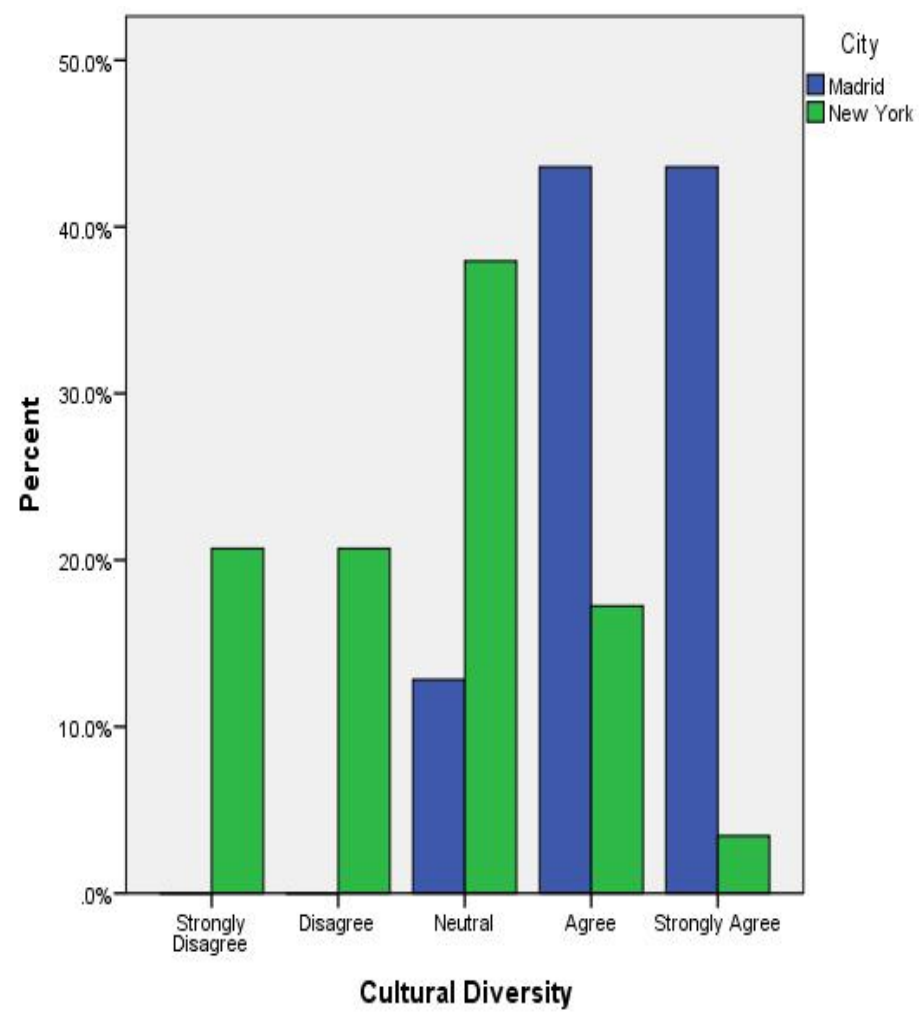

Fig. 3. Responses about students' consideration of cultural diversity during the project.

The responses to the open question regarding cultural diversity show how this facet of the experience has affected the participants. These commentaries were made by students from the program in New York.

- (I observed) patients from different ethnic backgrounds with language barriers, patients with various religious/cultural beliefs (skin exposure, female therapist preference, absence due to shabbat).

- I encountered different cultures. I interpreted for Spanish speaking patients and employees. I was taught different ways to interact with patients from different backgrounds according to their needs.

- Using my own experiences in conjunction with my classmates gave me a better understanding of the importance of diversity and respecting it.

Students from Madrid made the following observations:

- We have dealt with three countries in total: Spain, Kenya and America. The result has been very satisfactory.

- I have found that the culture (of Kenya) is very different, especially in reference to learning and the means available for it, as well as clothing, food and values. 
- Our western culture is accustomed to using computers and the internet and everything is almost instantaneous. Other cultures like Kenya do not have these resources, and this gives them a different mentality

Although none of the comments specifically related the use of the ePortfolio with cultural diversity, the observations of the students seem to indicate that they have learned from this aspect of their respective projects.

\subsection{Feedback}

As previously note, the question regarding feedback received from fellow students and professors ranked the lowest mean of all responses for the group in New York, while having the second highest mean for the responses in Madrid. This disparity is also reflected in the large chi-square value $(\mathrm{X} 2(4$, NMadrid $=39$, NNewYork $=29)=$ 40.06, $\mathrm{p}<.01$.). A graphical representation of the responses follows in Figure 4.

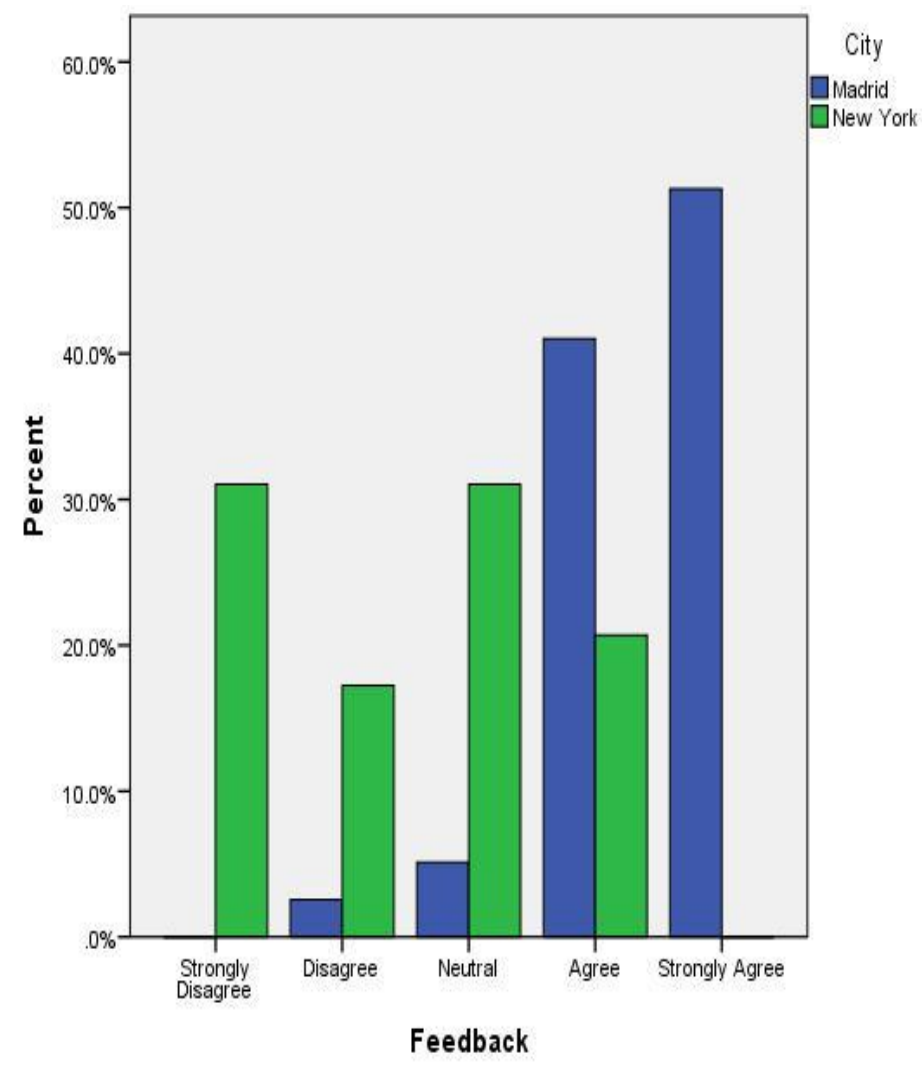

Fig. 4. Feedback received during the project. 
The comments left in the open question about feedback help to clarify the students' experiences within the two programs. Some examples of responses from the New York group follow:

- I feel like I received little to no feedback and what I did receive was cursory because someone was assigned the task of giving it to me.

- Professors will look at it, but they seldom write feedback on ePortfolio for us.

- The teacher has been very involved in this project, helping us with any question or need we have had.

\subsection{Reflection}

Students were asked to agree or disagree with a statement regarding having had structured opportunities to reflect on the Service-Learning project through the ePortfolio. A chi-square test of independence was performed to examine the relationship between Madrid and New York with regard to opportunities for reflection during the project. The relation between these variables was significant, $\mathrm{X}^{2}\left(4, \mathrm{~N}_{\text {Madrid }}\right.$ $\left.=39, \mathrm{~N}_{\text {NewYork }}=29\right)=31.89, p<.01$. A graphical representation of responses follows in Figure 5.

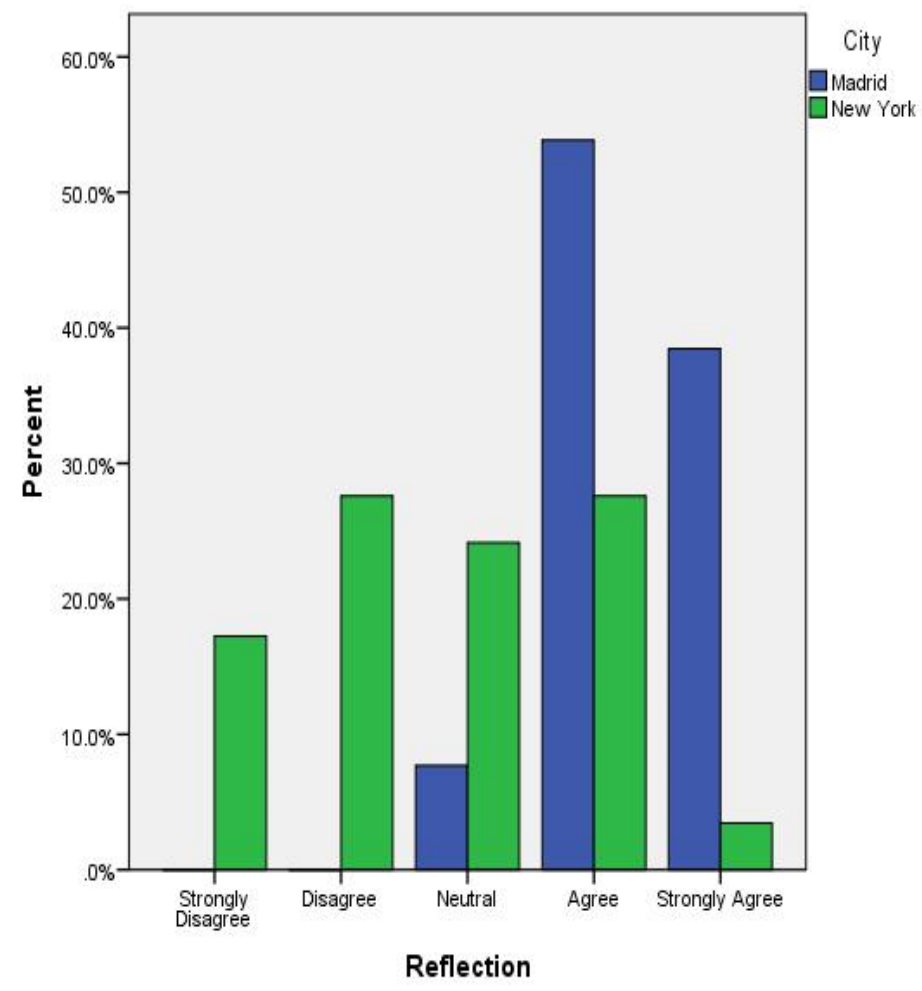

Fig. 5. Opportunities for reflection 
However, upon reviewing the responses for the corresponding open question, we found that of the six responses left by the group of New York, four gave a positive evaluation of the opportunities for reflection. Examples follow:

- Peer review reminded me of clinical ethics and how to act on it.

- Helped me to reflect on my performance and things I need to improve.

As expected, the written responses from the Madrid group were positive. There was one response, however, that particularly demonstrates the power of reflection through ePortfolio:

- It has helped me realize that you can help from here. And of the resources we have and what they have, which is nothing in comparison.

\subsection{Relevance of learning through real-world applications}

Next, students were asked to consider whether or not the ePortfolio provided opportunities to discover relevance of learning through real-world applications. A chisquare test of independence was performed to examine the relationship between Madrid and New York with regard to real world experiences during the project. The relation between these variables was significant, X2 (4, NMadrid $=39$, NNewYork = $29)=29.39, \mathrm{p}<.01$. This item along with the previous one tied for the second highest mean for the New York group. As both programs boasted of hands-on opportunities to practice that was being taught in the classroom, it is interesting to see that both groups were able to use the ePortfolio as a tool to discover the relevance of their studies. A graphical representation follows.

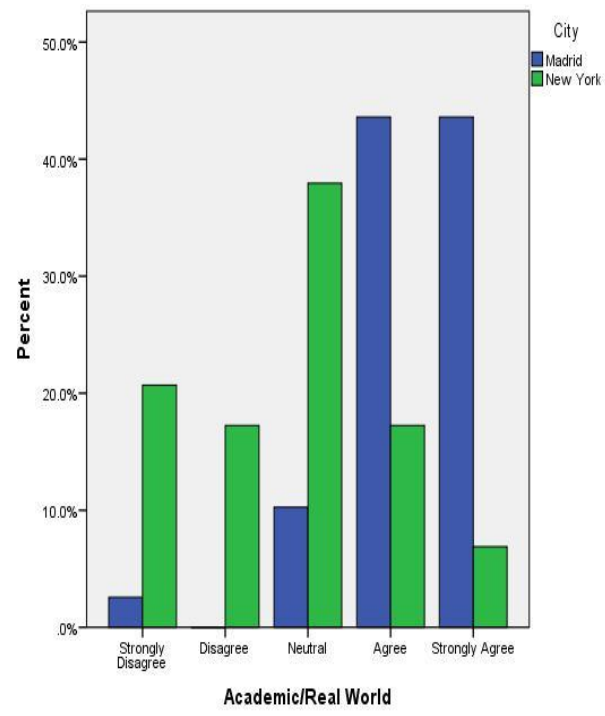

Fig. 6. Relevance of learning through real-world applications 
The comments left by both groups in response to this item were mostly positive and represent opinions and sentiments that are not easily discerned from the quantitative data. Some examples of the comments left by the New York group follow:

- Technology is always changing and ePortfolio helps as a timeline.

- Incorporating knowledge gained throughout the program and reinforcing it at my clinical setting e.g., physical modalities parameters and set ups; neuro/ortho exercises and interventions, mobility and w/c transfer training, gait deviations etc.

- I never used this application to its full extent, but I see the potential of information sharing opportunity and networking through the real-world applications.

\subsection{Demonstration of competencies}

In this item students were asked their level of agreement with having been able to make their digital competencies visible and to publicly demonstrate them. This item boasted the highest mean of the New York group. A chi-square test of independence was performed to examine the relationship between Madrid and New York with regard to opportunities for demonstration of competencies during the project. The relation between these variables was significant, X2 (4, NMadrid $=39$, NNewYork = $29)=14.18 \mathrm{p}=.007$. A graphical representation follows.

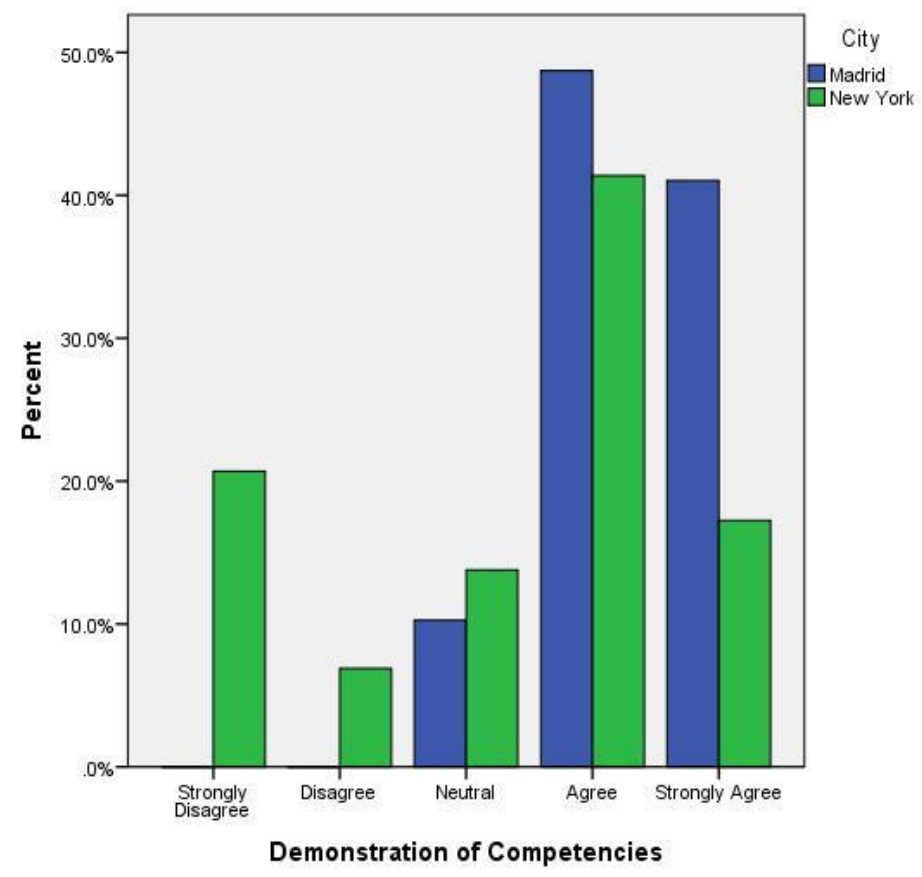

Fig. 7. Demonstration of Competencies. 
The students from both programs added valuable comments about the how they used the ePortfolio to demonstrate their abilities.

- I chose whom to share with, at first. I have now made it public to the LaGuardia community. I struggled with the idea of making it public while in school but am now very proud of my work and hope it can help others do the same. (New York)

- It is very structured and was easy to demonstrate them. (New York)

- By writing my experience during my 3 clinical rotations and make them public for anyone interested in this career. (New York)

- By making an attractive portfolio with many colors and very visual elements. (Madrid)

Students also made some observations that could be valuable when adapting the ePortfolio to the needs of the users.

- I don't think that ePortfolio is the platform I wish to share my competencies with future employers or other members of the public due to its elementary aesthetics and juvenile ideology that an employer wants to take the time to read completed assignments, personal goals, etc. (New York)

- I did not because no one was really interested in navigating the cumbersome, clunky, old site. (New York)

\section{$5 \quad$ Correlations}

Due to the non-parametric and ordinal nature of the data, the Kendall's taub calculation was used to assess correlations between the high-impact behaviors. Correlations were calculated on the scores at a whole, and then by city. For the purposes of this analysis, only moderate $(.40 \leq \mathrm{r} \tau \geq .59)$, strong $(.60 \leq \mathrm{r} \tau \geq .79)$, and very strong $(.80 \leq \mathrm{r} \tau \geq 1.0)$ correlations are considered.

One of the more striking observations is that there are three high-impact behaviors that are positively correlated with all of the others, namely spending time on the project, interaction with peers and professors, and relating academic learning to realworld experience. It is also interesting to note that the highest correlation for the combined scores is between opportunity for reflection and relation of learning through real-world experiences $(\mathrm{r} \tau=.69, \mathrm{p}<.01)$. The next highest correlation is between feedback and opportunities for interaction $(r \tau=.67, \mathrm{p}<.01)$. Table 3 is the correlation table for the combined responses. 
Table 3. Combined Correlations

\begin{tabular}{|l|c|c|c|c|c|c|c|}
\hline & $\mathbf{1}$ & $\mathbf{2}$ & $\mathbf{3}$ & $\mathbf{4}$ & $\mathbf{5}$ & $\mathbf{6}$ & \multicolumn{1}{|c|}{$\mathbf{n}=68$} \\
\hline 1 & - & $.64 * *$ & $.57^{* *}$ & $.44^{* *}$ & $.55^{* *}$ & $.58^{* *}$ & $.43^{* *}$ \\
\hline 2 & $.64^{* *}$ & - & $.59^{* *}$ & $.68^{* *}$ & $.59^{* *}$ & $.60^{* *}$ & $.46^{* *}$ \\
\hline 3 & $.57^{* *}$ & $.59^{* *}$ & - & $.58^{* *}$ & $.62^{* *}$ & $.66^{* *}$ & $.28^{* *}$ \\
\hline 4 & $.44^{* *}$ & $.67^{* *}$ & $.58^{* *}$ & - & $.66^{*}$ & $.60^{* *}$ & $.30^{* *}$ \\
\hline 5 & $.55^{* *}$ & $.59^{* *}$ & $.62^{* *}$ & $.66^{* *}$ & - & $.69^{* *}$ & $.38^{* *}$ \\
\hline 6 & $.58^{* *}$ & $.60^{* *}$ & $.66^{* *}$ & $.59^{* *}$ & $.70^{* *}$ & - & $.44^{* *}$ \\
\hline 7 & $.43^{* *}$ & $.46^{* *}$ & $.28^{* *}$ & $.30^{* *}$ & $.38^{* *}$ & $.44^{* *}$ & - \\
\hline
\end{tabular}

Note. $* * \mathrm{p}<.01 ; 1=$ Time; $2=$ Interaction; $3=$ Cultural Diversity; 4= Feedback; 5=Reflection; $6=$ Academic/Real World; $7=$ Demonstration of Competencies

Lessons Learned from the Madrid Cohort. The data indicated the following key findings:

- The students in Madrid reported a high level of interaction and feedback, and the data suggest that other high-impact behaviors were also more prevalent. These findings are further confirmed by the discovery of strong positive correlations between the same variables.

- The strongest correlation was that between time and interaction $(r \tau=.49, \mathrm{p}<.01)$, which indicates that when the amount of interaction with peers and professors increased, so did the time spend on the project. This is not unexpected as interaction does require time on the part of the student. The second of three statistically significant correlations drawn from the data from Madrid is between reflection and the relating of academic learning with real-world experiences $(\mathrm{r} \tau=$ $.48, \mathrm{p}<.01)$. This implies that students reflect more on their learning when realworld experiences are involved. The third statistically significant correlation observed in the data from Madrid is that of time spent on project and relation of learning through real-world experiences $(\mathrm{r} \tau=.40, \mathrm{p}<.01)$.

- The students in Madrid perceived a more active participation by faculty. Comments revealed that this interaction was not limited to evaluation, but that the ePortfolio was also used to request clarification and input.

- Students reported a high level of structured opportunities to reflect on the ServiceLearning project through the ePortfolio both in the quantitative survey, as well as in their written responses. They also stated that the Service-learning activity combined with the tasks completed in the ePortfolio helped them think about cultural diversity.

- The data confirm the importance of providing students a way to relate their classroom learning with real-world experiences. These are the types of connections that help students evolve into deliberate and purposeful learners (Eynon and Gambino, 2017, p. 46-48). This high-impact behavior, along with interaction, was also positively correlated to each of the other HIPs examined.

Lessons learned from the New York cohort: The data suggested several key findings. 
- PTA Students did not feel they need to exert significant amount of time in their ePortfolio work during their clinical internship. This is most likely due to the longitudinal nature of the PTA Student Professional ePortfolio. Students' effort in developing and utilizing ePortfolio was dispersed throughout the tenure of their study. In fact, the most challenging time with ePortfolio was at the beginning when they were first exposed to the platform and had to learn about its functions and features. Furthermore, most of the recursive and intensive work were done during their Capstone study prior to their clinical internship.

- PTA Students did not utilize ePortfolio in any significant way to interact with peer and faculty. Due to the close-knit nature of the program where a cohort of 20 students admitted in a given semester will be studying together, along with the entire PTA faculty team, throughout the clinical phase of study on campus, their interaction with peer and faculty was face-to-face on a daily basis. They attended the same classes and practiced in the same labs at the same time every day. The ongoing comradery and collegial exchanges were so abundant that they saw little need for additional interaction via their ePortfolio. They mostly saw the ePortfolio as a professional space for reflection and professional development.

- Students saw ePortfolio with little value in exposing or supporting cultural diversity. Students and faculty in New York had direct interacts with people from over 100+ countries and ethnic backgrounds on campus daily. It's much the same with their internship experiences at the community clinical sites. These ongoing exposures made using ePortfolio or online interactions to experience or demonstrate cultural competence far less vivid and dynamic. Once again, they did not rely on ePortfolio to provide any support in this regard.

On the contrary, there were two areas where the New York cohort clearly demonstrate the value of ePortfolio in their educational experience.

i) Students saw ePortfolio as a worthy reflective tool for their learning experience. Below are some examples of the many reflective evidence found among the PTA students:

- "Normally, people will share some very interesting experience, or very unpleasant experience in the ePortfolio, from which I can learn how others respond and how others handle, so that I can have a rough idea about how I could perform when I am in the same situation."

ii) Students considered ePortfolio with the greatest value as a way to demonstrate competencies.

- "I chose whom to share with, at first. I have now made it public to the LaGuardia community. I struggled with the idea of making it public while in school but am now very proud of my work and hope it can help others do the same."

Because the PTA program placed significant emphasis on developing students' didactic knowledge and clinical competence, ePortfolio continued to serve a complementary role to student learning. It was not a coincidence that both the 
students and the faculty shared the same view of ePortfolio as a pedagogical tool best suited for reflection and assessment of learning.

\section{Conclusion}

This research has confirmed the valuable role that the ePortfolio can play when combined with another high-impact practice. High-impact practices in general aim to foment the growth and development of the student through the connection and interaction between academic and real-life experiences. Both programs gave students unique opportunities to serve others outside of the classroom. The ePortfolio was then used as a central hub and platform for students and faculty to facilitate integration of interaction, feedback, and reflection. Students used the ePortfolio as a place to record, not only their academic assignments, but also observations that related their academic learning to real world experiences. This ePortfolio was then used to document and demonstrate their acquired skills. It is precisely this type of integration that allows the ePortfolio to function as a relevant and advantageous meta high-impact practice.

Our statistical analysis sheds light on the relationship between seven high-impact behaviors present when two high-impact practices, such as the ePortfolio and ServiceLearning or Internship, are combined. The correlations, both combined and by city, demonstrate the importance of promoting two high-impact behaviors in particular, which are:

- Quality interaction between the students and the professors

- Providing opportunities to relate academic learning to real world experiences. When these two high-impact behaviors were maximized, our data suggest that the use of other high-impact behaviors examined in this study expanded as well.

This research also illuminated the important fact that even the most effective pedagogical tool must be calibrated to the unique quality of the student needs and the consistent and thoughtful guidance from the faculty. Without them, ePortfolio could just be busy work with very low impact.

It is truly "the best of times" to have versatile and sophisticated pedagogical tools such as ePortfolios that are widely available in education. However, as with any practice, it requires deliberate, consistent, and conscientious planning, support and implementation by faculty and institution, in order to ensure that students and educators can harness the full potential of ePortfolio.

\section{$7 \quad$ References}

[1] Johnson, S. R., \& Stage, F. K. (2018). Academic Engagement and Student Success: Do High-Impact Practices Mean Higher Graduation Rates? Journal of Higher Education, 89(5), 753-781. https://doi.org/10.1080/00221546.2018.1441107

[2] Kolenovic, Z., Linderman, D., \& Karp, M. M. (2013). Improving Student Outcomes via Comprehensive Supports: Three-Year Outcomes From CUNY's Accelerated Study in 
Associate Programs (ASAP). Community College Review, 41(4), 271-291. https://doi.org/ $10.1177 / 0091552113503709$

[3] Kinzie, J. (2013). Taking Stock of Capstones and Integrative Learning. Peer Review, 15(4), 27-30.

[4] Northey, G., Govind, R., Bucic, T., Chylinski, M., Dolan, R., \& van Esch, P. (2018). The effect of "here and now" learning on student engagement and academic achievement. British Journal of Educational Technology, 49(2), 321-333. https://doi.org/10.1111/ bjet.12589

[5] Shapiro, D., Dundar, A., Wakhungu, P. K., Yuan, X., Nathan, A., \& Hwang, Y. (2015). Completing college: A national view of student attainment rates-fall 2009 cohort (Signature Report No. 10). Herndon, VA: National Student Clearinghouse Research Center.doi:10.1080/10691316.2013.789658

[6] Kuh, G. (2008). High-Impact Educational Practices, What they Are, Who Has Access to Them, and Why They Matter. Washington, DC: Association of American Colleges and Universities.

[7] Riehle, C. F., \& Weiner, S. A. (2013). High-Impact Educational Practices: An Exploration of the Role of Information Literacy. College \& Undergraduate Libraries, 20(2), 127-143. https://doi.org/10.1080/10691316.2013.789658

[8] American Association of Colleges and Universities (AAC\&U) (2018). High-impact educational practices: A brief overview. Retrieved from http://www.aacu.org/leap/hip.cfm

[9] Eynon, B., \& Gambino, L. (2017). High-Impact ePortfolio Practice: A Catalyst for Student, Faculty, and Institutional Learning. Sterling, Virginia: Stylus.

[10] Kuh, G., O'Donnell, K., \& Schneider, C. G. (2017). HIPs at Ten. Change: The Magazine of Higher Learning, 49(5), 8-16. https://doi.org/10.1080/00091383.2017.1366805

[11] Eynon, B., \& Gambino, L. (2018). Catalyst in Action: Case Studies of High Impact EPortfolio Practice. Sterling, Virginia: Stylus.

[12] Kuh, G., \& O'Donnell, K. (2013). Ensuring Quality \& Taking High-Impact Practices to Scale. Washington, DC: Association of American College \& Universities.

[13] Finley, A. (2011). Assessment of high-impact practices: Using findings to drive change in the compass project. Peer Review, 13(2), 29.

[14] Finley, A., \& McNair, T. (2013). Assessing Underserved Students' Engagement in HighImpact Practices. With an Assessing Equity in High-Impact Practices Toolkit. Association of American Colleges and Universities.

[15] Hubert, D., Pickavance, J., \& Hyberger, A. (2015). Reflective E-portfolios: One HIP to Rule Them All? Peer Review, 17(4), 15.

[16] Kuh, G. D., Gambino, L. M., Ludvik, M. B., \& O'Donnell, K. (2018). Accentuating Dispositional Learning from HIPs Using ePortfolio. Assessment Update, 30(3), 8-9. https:// doi.org/10.1002/au.30136

[17] Soria, K., \& Johnson, M. (2017). High-Impact Educational Practices and the Development of College Students' Pluralistic Outcomes. College Student Affairs Journal, 35(2), 100116. https://doi.org/10.1353/csj.2017.0016

[18] Springer, J. T., \& Hatcher, J. A. (2017). Assessing High-Impact Educational Practices: Quality, Diversity, and Inclusive Excellence. Assessment Update, 29(5), 6-12. https://doi. org/10.1002/au.30108

[19] Eynon, B., Gambino, L., \& Torok, J. (2014). What Difference Can ePortfolio Make? A Field Report from the Connect to Learning Project. International Journal of ePortfolio, 4(1), 95-114. 
[20] Diller, K. R., \& Phelps, S. F. (2008). Learning outcomes, portfolios, and rubrics, oh my! Authentic assessment of an information literacy program. Libraries and the Academy, 8(1), 75-89. https://doi.org/10.1353/pla.2008.0000

[21] Benedict, B.J. \& Rust, M.M. (2016). IUPUI Taxonomy for Internship Courses. Retrieved from https://rise.iupui.edu/resources/course-development/taxonomies/

[22] Ebacher, C. (2013). Taking Spanish into the Community: A Novice's Guide to ServiceLearning. Hispania,96(2), 397-408. https://doi.org/10.1353/hpn.2013.0064

[23] Hahn, T.W., Hatcher, J.A., Price, M.F., Studer, M.L. (2016). IUPUI Taxonomy for Service-Learning Courses. Retrieved from https://rise.iupui.edu/resources/coursedevelopment/taxonomies/

[24] O'Neill, N. (2010). Internships as a high-impact practice: Some reflections on quality. Peer Review, 12(4), 4.

[25] Hanum, S. R., Che-Ani, A. I., Johar, S., Ismail, K., \& Razak, M. Z. A. (2016). ePortfolio: A descriptive survey for contents and challenges. International Journal of Emerging Technologies in Learning (iJET), 11(01), 4-10. https://doi.org/10.3991/ijet.v11i01.4900

[26] Alfageme, B. (2007). El portafolio reflexivo: metodología didáctica en el EESS. Revista Educatio Siglo XXI, 25, 209-226.

[27] Chouquet, K. S. (2017). La eliminación del libro de texto y el uso del portafolio en la asignatura de música en ESO: una experiencia para incrementar la calidad del aprendizaje y la motivación del alumnado. Revista Educatio Siglo XXI, 35(1), 9. https://doi.org/10.60 $\underline{18 / \mathrm{j} / 286201}$

[28] Cleveland, R. E. (2018). Using Digital Portfolios: Reflection, Assessment \& Employment. TechTrends, 62(3), 276-285. https://doi.org/10.1007/s11528-018-0262-0

[29] Panos, A. (2015). Reflections from Preservice to Novice Teaching: One Perspective on the Role of ePortfolios. Theory Into Practice, 54(4), 292-300. https://doi.org/10.1080/004058 41.2015.1076692

[30] Slepcevic-Zach, P., \& Stock, M. (2018). ePortfolio as a tool for reflection and selfreflection. Reflective Practice, 1-17. https://doi.org/10.1080/14623943.2018.1437399

[31] Watson, C. E., Kuh, G. D., Rhodes, T., Light, T. P., \& Chen, H. L. (2016). ePortfolios-The eleventh high impact practice. International Journal, 6(2), 65-69.

[32] Wetcho, S., \& Na-Songkhla, J. (2019). The Different Roles of Help-Seeking Personalities in Social Support Group Activity on E-Portfolio for Career Development. International Journal of Emerging Technologies in Learning, 14(2). https://doi.org/10.3991/ijet.v14i0 2.8718

[33] Ciesielkiewicz, M. (2019). Education for employability: the ePortfolio from school principals' perspective. On the Horizon, 27(1), 46-56. https://doi.org/10.1108/oth-01-2019$\underline{0001}$

[34] Kahn, S. (2014). E-Portfolios: A look at where we've been, where we are now, and where we're (possibly) going. Peer Review, 16(1), 4-7. https://doi.org/10.1111/psyp.12352

[35] Samardzija, A. C., \& Balaban, I. (2014). From classroom to career development planning: Eportfolio use examples. International Journal of Emerging Technologies in Learning (iJET), 9(6), 26-31. https://doi.org/10.3991/ijet.v9i6.4027

[36] Weber, K., \& Myrick, K. (2018). Reflecting on Reflecting: Summer Undergraduate Research Students' Experiences in Developing Electronic Portfolios, a Meta-High Impact Practice. International Journal, 8(1), 13-25.

[37] Chan, C. (2012). Using the ePortfolio to Complement Standardized Testing in a Healthcare Professional Program: Better Education or More Busy Work? International Journal of ePortfolio, 2(2), 149-162. 
[38] Brownell, J. E. \& Swaner, E. (2010). Five high-impact practices: Research on learning outcomes, completion, and quality. Washington, DC: Association of American Colleges \& Universities. https://doi.org/10.1111/teth.12035

[39] CAPTE. Evaluative Criteria (2014). Commission on Accreditation in Physical Therapy. Retrieved from http://www.capteonline.org/uploadedFiles/CAPTEorg/About_CAPTE/Re sources/Accreditation_Handbook/EvaluativeCriteria_PTA.pdf. https://doi.org/10.1097/00 001416-201201000-00002

\section{Authors}

Monika Ciesielkiewicz, Ph.D., Associate Professor, School of Education, Department of Applied Didactics; Villanueva-Complutense University of Madrid, Spain. Address: Villanueva-Universidad Complutense Madrid. Costa Brava 2, 28034. Madrid, Spain. Email: mciesielkiewicz@ villanueva.edu

Clarence Chan, Ph.D., Director of the Physical Therapist Assistant Program at LaGuardia- City University of New York. Address: 31-10 Thomson Ave, Long Island City, NY 11101, USA. Email: cchan@lagcc.cuny.edu

Guiomar Nocito, Ph.D., Associate Professor; School of Psychology; Department of Psychopedagogy; Villanueva-Complutense University of Madrid, Spain. Address: Villanueva-Universidad Complutense Madrid. Costa Brava 2, 28034. Madrid, Spain. Email: gnocito@villanueva.edu

Article submitted 2019-10-28. Resubmitted 2019-12-28. Final acceptance 2019-12-28. Final version published as submitted by the authors. 